\title{
Chemical signatures of multi-species foraging aggregations are attractive to fish
}

\author{
Jennifer L. DeBose ${ }^{1,2, *}$, Valerie J. Paul ${ }^{1}$ \\ ${ }^{1}$ Smithsonian Marine Station at Fort Pierce, Florida 34949, USA \\ ${ }^{2}$ Present address: Catchment to Reef Research Group, Centre for Tropical Water \& Aquatic Ecosystem Research \\ (TropWATER), James Cook University, Townsville, Queensland 4811, Australia
}

\begin{abstract}
Fish navigate a sea of chemical signatures, which can guide their movements through their environment. Chemoreception is integral to how larval fish find reef habitat and adult fish find home. Yet, the chemicals responsible for driving fish behavior are largely unknown, and the chemical seascapes through which fish navigate are changing with shifting environmental conditions. To investigate the possible suite of chemical cues employed by fishes in their search for foraging hot-spots, we collected $10 \mathrm{l}$ samples of water from the center of natural foraging aggregations. These aggregations were composed of multiple fish species from several trophic levels over the reefs of Belize. We then conducted bioassays on wild-caught Abudefduf saxatilis $(\mathrm{N}=84)$ in laboratory flow tanks using previously frozen seawater samples and extracted compounds from foraging aggregations and paired control sites. Capturing seawater from the midst of natural foraging aggregations, filtering this over $\mathrm{C} 18$ resin, and presenting the eluted compounds to a reef fish elicited a significant behavioral response of spending more time in water that contained C18 extracts from fish aggregations compared to controls $(p=0.03)$. These results indicate that chemical cues collected within the middle of multi-species fish foraging aggregations are attractive to adult reef fish and suggest that chemical signatures associated with foraging aggregations might be important olfactory guides for fish.
\end{abstract}

KEY WORDS: Chemical ecology $\cdot$ Fish aggregation $\cdot$ Coral reefs $\cdot$ Plankton $\cdot$ Bioassay $\cdot$ C18

\section{INTRODUCTION}

Reef fish navigate a vast chemical seascape in their search for food, shelter and mating opportunities. Chemoreception, through taste and smell, is integral to how fish maneuver throughout their lives, from larval stages (e.g. Sweatman 1988, Elliott et al. 1995, Gerlach et al. 2007, Dixson et al. 2011, Lecchini et al. 2013) to adults (reviewed by DeBose \& Nevitt 2008). However, the chemicals responsible for driving their behaviors are largely unknown, and, along with the chemoreceptive abilities of fish, are likely changing. The chemical seascapes are shifting due to changes in benthic community structure - from those of coraldominated reefs to algae-dominated reefs (see Gleason et al. 2009, Lecchini et al. 2013) — and changes in fish community dynamics and population abundances, considering that conspecifics produce attractive compounds (e.g. salmon [Nordeng \& Bratland 2006], reef fish [Sweatman 1988, Lecchini et al. 2005a,b], and lamprey [Vrieze \& Sorensen 2001]). Further, increases in environmental pollutants can adsorb compounds, such as pheromones, thereby reducing their availability for chemical signaling (see Mesquita et al. 2003; reviewed by Lürling 2012). Coupled with these changes in the chemical environment, the ability of fish to utilize these chemical cues may be at risk through disruption to their chemosensory systems (Lürling \& Scheffer 2007), especially under changing environmental conditions such as increased sedimentation and turbidity (Wenger et al. 2011) and ocean acidification (e.g. Munday et al. 2009, Nilsson et al. 2012). 
Though previous studies have highlighted the ability of fish to recognize and attract to ecologically relevant odors, such as reef water (e.g. Gerlach et al. 2007, Lecchini et al. 2013), 'home' water (e.g. Dittman \& Quinn 1996, Mitamura et al. 2005), amino acids (e.g. Davis et al. 2006, Hara 2006), and conspecifics (e.g. Vrieze \& Sorensen 2001, Nordeng \& Bratland 2006), there are very few studies geared at understanding the natural chemical signatures produced by fish aggregations and how these specific signatures affect fish behavior (e.g. DeBose \& Nevitt 2007, DeBose et al. 2008, 2010). Recent work hypothesized that roaming fish may depend on plumes of dimethylsulfoniopropionate (DMSP) to 'eavesdrop' on the foraging behavior of other fish (DeBose et al. 2008, 2010). In these studies, DMSP was explored as a specific, planktonreleased compound of interest, but DMSP is just one of a potentially broad suite of chemicals released from foraging events. Our aim was to test whether or not fish (Abudefduf saxatilis) in a choice chamber are preferentially attracted to the chemical cues from seawater collected from naturally occurring foraging aggregations and to narrow in on the nature of particular chemicals of interest as a step toward identifying other ecologically important compounds.

\section{MATERIALS AND METHODS}

\section{Fish aggregations}

Using open-circuit SCUBA, we spent $\sim 30$ min per dive searching for foraging aggregations over open water along the edge of the drop-off of the barrier reef around Carrie Bow Cay, Belize. We defined a foraging aggregation as a group of fishes consisting of at least 100 individuals (mean \pm 1 SE: $559 \pm 58$ ind.) and at least 4 species (mean: $7 \pm 0.3$ spp.), which were actively foraging along the Belize barrier reef. Depths of aggregations ranged between 3.3 and $20.9 \mathrm{~m}$ (mean: $14.2 \pm 0.5 \mathrm{~m}$ ). Aggregations were visually surveyed using a modified instantaneous stationary point count method, whereby all fish within the circumference of the aggregation were counted and all species were identified. Surveys were conducted from outside and down-current of the aggregations prior to collecting water samples.

\section{Water samples}

After conducting visual surveys, we collected $10 \mathrm{l}$ of seawater, using 2 handheld 51 Niskin bottles, from the center of actively foraging aggregations $(n=40)$. We also collected control water $\sim 30 \mathrm{~m}$ up-current and from the same depth as the aggregation. Though fish would startle when the Niskin bottles were snapped closed, in all cases of collection, the aggregation would reform after the diver retreated back to the shallow reef edge. Immediately after collection, water samples were transferred via silicone tubing into two $20 \mathrm{l}$ carboys and placed in the shade under black plastic. Upon returning to the Carrie Bow Cay field station (usually within $1 \mathrm{~h}$ of collection), samples were gravity filtered through Nitex mesh (180 and $36 \mu \mathrm{m})$ to remove zooplankton and larger microplankton, and $1 \mathrm{l}$ was then frozen $\left(-20^{\circ} \mathrm{C}\right)$. Five to 81 (equal volumes of paired aggregation and control water) were passed over $5 \mathrm{~g}$ C18 flash cartridges (Varian Bond Elut), and $2 \mathrm{l}$ were passed over $5 \mathrm{~g}$ Diaion HP20 resin. C18 and HP20 resins were then frozen. Samples were brought back to the Smithsonian Marine Station in Fort Pierce, Florida, and eluted from C18 with a 50:50 mixture of $100 \%$ HPLC-grade methanol $(50 \mathrm{ml})$ and ethyl acetate $(50 \mathrm{ml})$ and from HP20 with $100 \%$ HPLC-grade methanol. Extracts were dried, and the solid extract was weighed then frozen. Similar methods of seawater extraction have been employed in other studies (e.g. Fine \& Sorensen 2005, Lecchini et al. 2005b). Prior to conducting bioassays, individual extracts were re-dissolved in a solution of $1 \mathrm{ml}$ of $100 \%$ methanol and $200 \mu \mathrm{l}$ of distilled water. From these extract solutions, $200 \mu \mathrm{l}$ of C18 or $500 \mu \mathrm{l}$ of HP20 was then added to 11 of $5 \mu \mathrm{m}$ filtered seawater to reconstitute concentrations that approximated those in the original seawater samples. Positive-control food extract samples were prepared by soaking $7.3 \mathrm{~g}$ pellets (Kent Marine Platinum Reef Carnivore medium pellets) in $1 \mathrm{l}$ filtered seawater overnight, then filtering over $20 \mu \mathrm{m}$ mesh. Frozen whole aggregation and control seawater samples were allowed to thoroughly thaw and come to background water temperature prior to trials. Background water temperatures averaged $24.0^{\circ} \mathrm{C}\left( \pm 0.2^{\circ} \mathrm{C}\right)$.

\section{Fish bioassays}

For the bioassay, we collected sergeant major Abudefduf saxatilis by cast-net from Fort Pierce and Jupiter Inlets, Florida. We chose to use A. saxatilis because they were seen in multi-species fish aggregations in Belize, are planktivorous, reef-associated damselfish, could be collected locally without the use of anesthetics, which may impair fish chemosensory abilities, and are resilient to captivity. After field cap- 
ture, A. saxatilis individuals were allowed $7 \mathrm{~d}$ to acclimate before trials. Fish were fed frozen brine shrimp and flake food ad libitum but were fasted $24 \mathrm{~h}$ prior to testing. Fish sizes ranged from 4.5 to $7.5 \mathrm{~cm}$ $\mathrm{TL}($ mean $\pm \mathrm{SE}: 6.0 \pm 0.1 \mathrm{~cm})$.

The bioassay was conducted at the Smithsonian Marine Station at Fort Pierce, in a Plexiglas flow tank $(107 \times 25.5 \times 15.5 \mathrm{~cm}$; Fig. 1$)$ with 2 inflows and opposite outflows, plumbed with filtered seawater from the Fort Pierce Inlet. The upstream end of the tank was split by a partition running from the inflow to $35.5 \mathrm{~cm}$ downstream. The tank was fitted with $2 \mathrm{IV}$ bags to deliver separate experimental flows along each side of the tank. We reasoned that if $A$. saxatilis preferred a particular chemical signature, fish would spend more time investigating that particular flow or side of the tank.

Background water was sequentially filtered through a $10 \mu \mathrm{m}$ bag filter, inline carbon and $5 \mu \mathrm{m}$ ceramic filters before entering the tank via 2 inlets on either side of the partition. Water passed through a baffle, or flow-straightener, then exited the tank via 2 outflows directly opposite the inlets at $\sim 61 \mathrm{~min}^{-1}$. Separation of flows was verified daily by dye test. The tank was housed under a wooden support stand, which was covered in black plastic and illuminated by infrared lights to remove outside visual cues. However, because these fish are active during the day, holes were drilled on top of the structure to allow for dim illumination from fluorescent lighting above. A camcorder (Sony) was placed above the tank, over a Plexiglas window, and remotely controlled. The trials were recorded and scored by an observer who was blind to the treatment, using JWatcher software (v1.0, Macquarie University/ UCLA).

Whole-water or re-dissolved extracts and paired controls were delivered at $11 \mathrm{~min}^{-1}$ into the pre-

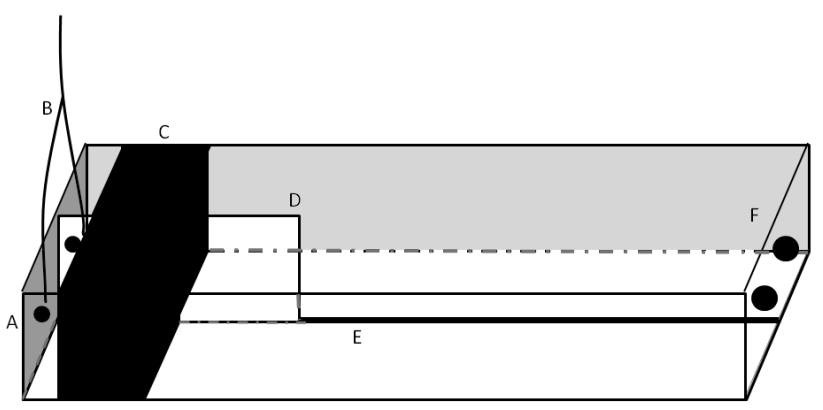

Fig. 1. Flow tank configuration. A: Tank inflow(s); B: IV tubing delivering experimental waters/extracts into pre-baffle area of flow tank; C: baffle, or flow-straightener; D: Plexiglas wall separating each side/flow of the tank; E: tape line demarcating either side/flow of the tank; F: outflows to the drain baffle end of the tank via 2 IV bags. Paired fieldcollected aggregation and control water samples (or extracts) were used for each trial, so an individual fish was tested against one aggregation and its paired control per trial. All fish were naïve to both the flow tank and experimental testing. At the start of each trial, a single fish was placed in the tank and allowed to acclimate for $30 \mathrm{~min}$. At $30 \mathrm{~min}$, flows from the IV bags were initiated. These flows were mixed with incoming background seawater, then passed through the baffles or flow straighteners, before moving into the testing arena of the tank. The first filaments of odor (as seen via dye tests) would immediately pass through the baffles, and by 1 min into the release, a fully mixed flow moved through each side of the tank until reaching the outflow, with a clear division between the treatment and control flows. During the minute of release and the minute during testing, the fish were most often moving throughout the tank and disrupting the separated flows. By 2 min after the initial release, the treatment and control plumes were mixing together within the downstream arena, and clean water was moving through the baffles. Behavior was analyzed for $1 \mathrm{~min}$ after the initial $1 \mathrm{~min}$ experimental release (i.e. the second full min after release) when the flows into each side of the tank were most clearly separated. If fish appeared stressed (e.g. floating up to the surface or backed into the outflow corner) throughout the acclimation period and trial, or if fish did not sample both sides of the tank during the first minute of release, the trial was discarded $(n=3)$. A line placed down the center of the tank was the basis for the scored behavior of 'crossing' into one side of the tank (Fig. 1). A 'cross' was counted once the head of the fish (i.e. the posterior end of the operculum) moved over the outer edge of the tape line (i.e. from one side of the tank into the other). The side in which experimental chemicals were released alternated between trials so that each side was equally used as 'experimental' and 'control'. At least 30 min passed between subsequent trials, which allowed for complete flushing of experimental waters from the tank.

\section{Statistical analyses}

Fish aggregation composition (total number and species richness) was compared among sampling trips with ANOVA (Statistica 7, Statsoft) to test for any significant shifts in aggregation composition which might affect the chemical composition of the water samples. Overall fish choice, spending 
$>0.5$ min of the 1 min trial period in one flow or side of the tank, was tested against a binomial distribution (probability mass function, $\mathrm{p}=0.5, \alpha=0.05$ ). The degree of preference, or the proportion of time fish spent in each experimental flow during the $1 \mathrm{~min}$ trial period, was analyzed using a 1 -sample $t$-test (Statistica 7, Statsoft). Variation in sample size for each trial was due to availability of each type of experimental water (e.g. $16 \mathrm{l}$ of whole frozen seawater samples, $39 \mathrm{C} 18$ extract samples, etc.) coupled with the number of valid trials used in the final analysis.

\section{RESULTS}

As a general description of fish behavior in these trials, when fish were placed in the down-current section of the tank, they spent the majority of the 30 min acclimation period swimming the length and up into both 'arms' of the tank. Once the trial began, at initial release of the experimental flows, fish generally reacted to the change in chemical environment (e.g. swimming slightly backwards then forwards, 'sniffing', crossing into each side of the tank) and then continued to swim throughout the tank and did not tend to position themselves solely in one side of the tank. However, during the second min after release and depending on the treatment, fish did spend significantly more time in one treatment flow than the other.

Abudefduf saxatilis preferred the $\mathrm{C} 18$ extract of aggregation water over that of control water $(\mathrm{n}=37$; binomial, $\mathrm{p}=0.04$, Fig. 2A) and spent significantly more time in the flow of $\mathrm{C} 18$ extract of aggregation water (1-sample $t_{36}=2.3, \mathrm{p}=0.03$; Fig 2B), similar to their response to the positive control food extract $\left(\mathrm{n}=7\right.$; binomial, $\left.\mathrm{p}=0.008 ; t_{6}=4.6, \mathrm{p}=0.004\right)$. Though more fish preferred whole, previously frozen seawater from aggregations ( $\mathrm{n}=15$; binomial, $\mathrm{p}=0.04$, Fig. 2A), they did not spend significantly greater time in aggregation water than in paired control water $\left(t_{14}=0.9, p=0.4\right)$, nor did they prefer HP20 extract from aggregations over controls $(\mathrm{n}=22$; binomial, $\mathrm{p}=$ $0.2 ; t_{21}=0.9, \mathrm{p}=0.4$ ).

In regards to composition of the sampled foraging aggregations, there was no significant difference in number $\left(F_{4,35}=2.17, \mathrm{p}=0.09\right)$ or species richness $\left(F_{4,35}=0.77, \mathrm{p}=0.55\right)$ of fish in the aggregations recorded over the separate months (Table 1). Aggregations were generally made up of the same fish species (e.g. creole wrasse Clepticus parrae, blue chromis Chromis cyanea, yellowtail snapper Осуu-
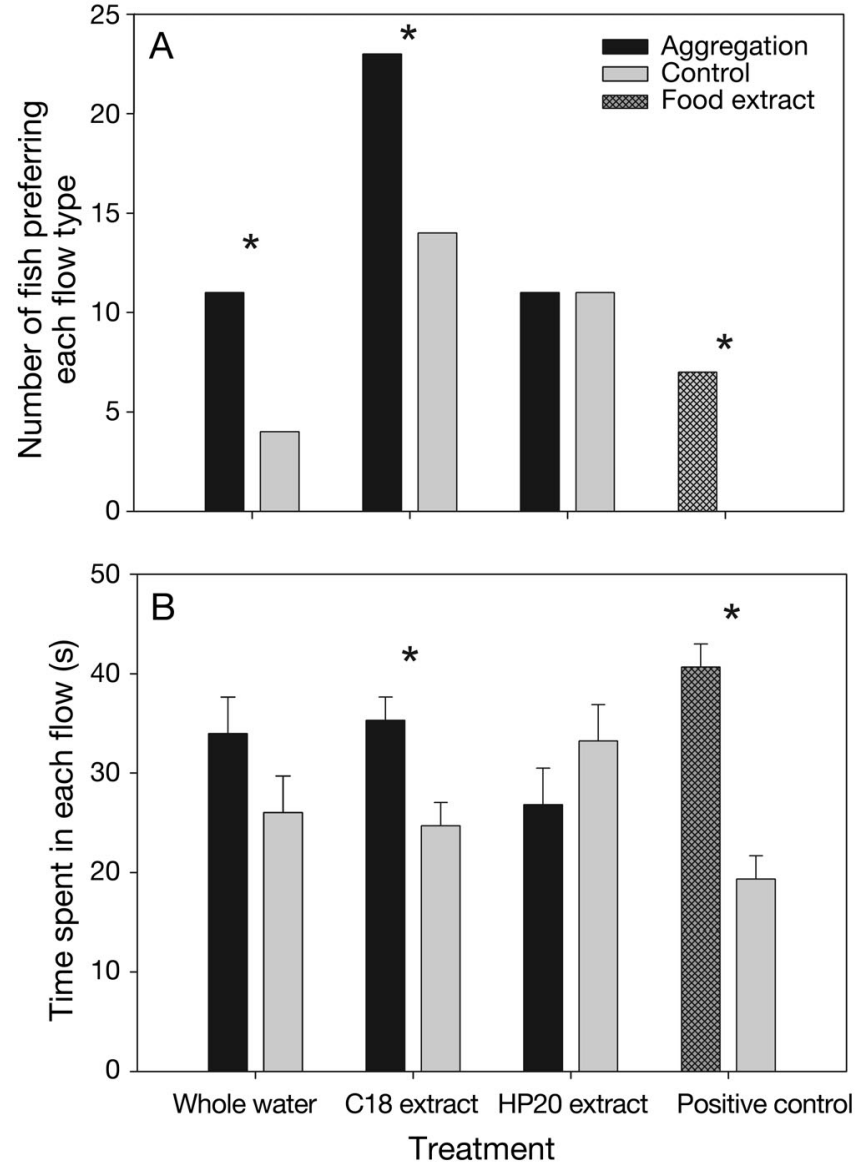

Fig. 2. (A) Number of Abudefduf saxatilis spending $>0.5 \mathrm{~min}$ in either flow (mean $\pm \mathrm{SE}$ ): whole aggregation water $(\mathrm{n}=$ $15), C 18$ extract $(n=37)$, HP20 extract $(n=22)$, or positive control (e.g. food extract) $(n=7)$, over paired controls. ${ }^{*} \mathrm{p}<$ 0.05 (binomial distribution). (B) Amount of time A. saxatilis spent in experimental flow (mean $\pm \mathrm{SE}$ ), i.e. whole aggregation water, C18 extract, HP20 extract, or food extract, over paired controls. ${ }^{*} \mathrm{p}<0.05$ (1-sample $t$-test)

rus chrysurus, bar jacks Caranx ruber and horse-eye jacks C. latus, boga Haemulon vittatum, dog snapper Lutjanus jocu, cero Scomberomorus regalis, groupers Mycteroperca spp., and various parrotfish Scaridae species), though several other species, including $A$. saxatilis, would also be present among the different aggregations. There were some differences in environmental conditions and fish behavior reflected in the difficulty of finding aggregations, which varied throughout the present study (see Table 1: frequency of occurrence). For example, in August 2010, there was a $53 \%$ chance of locating an aggregation on a single dive, compared to a low $22 \%$ chance in May 2011. Ease of locating aggregations seemed to depend on the tide cycle (lunar phase and stage of tide), presence of a current, and water clarity. For 
Table 1. Fish aggregation water collection information. Frequency of occurrence is the chance of finding an aggregation, determined by dividing the number of aggregations by the number of search-dives conducted per trip

\begin{tabular}{|lcccr|}
\hline $\begin{array}{c}\text { No. of } \\
\text { aggre- } \\
\text { gations }\end{array}$ & $\begin{array}{c}\text { Frequency } \\
\text { of occur- } \\
\text { rence (\%) }\end{array}$ & $\begin{array}{c}\text { Avg. number } \\
\text { of fish } \\
\pm \text { SE }\end{array}$ & $\begin{array}{c}\text { Avg. species } \\
\text { present } \\
\pm \text { SE }\end{array}$ \\
\hline Feb 10 & 8 & 37 & $461 \pm 84$ & $6.5 \pm 0.7$ \\
May 10 & 8 & 36 & $497 \pm 78$ & $7.8 \pm 0.8$ \\
Aug 10 & 8 & 53 & $723 \pm 153$ & $7.4 \pm 0.5$ \\
Nov 10 & 8 & 30 & $439 \pm 50$ & $8 \pm 0.8$ \\
May 11 & 8 & 22 & $675 \pm 53$ & $6.9 \pm 0.6$ \\
\hline
\end{tabular}

example, in May 2011, a diatom bloom occurred which reduced visibility, as well as perceived fish activity and aggregation formation, throughout that field season.

\section{DISCUSSION}

We found that extracts collected from $<10$ l of water passed over C18 elicited a significant positive response from fish. Abudefduf saxatilis spent significantly more time in water infused with C18 extracts from natural foraging aggregations than in water infused with C18 extracts from water samples collected at the same depth and reef habitat $\sim 30 \mathrm{~m}$ upcurrent of the aggregation. HP20 extracts did not elicit an attractive response from fish, which implies that compounds of interest were not retained by HP20. From the present study, we do not know if the attractive chemical cues derived from plankton, aggregating and foraging fish, or some combination. Yet, there was something attractive to our test subject, a reef-associated damselfish, in the waters we sampled amid the foraging aggregations in Belize.

Initial analysis of C18 extract by high performance liquid chromatography and proton nuclear magnetic resonance spectroscopy showed a multitude of compounds present in low concentrations (data not shown). C18 absorbs a range of chemicals, favoring more hydrophobic compounds. It has low affinity for amino acids and other extremely hydrophilic compounds, and the loss of these compounds when comparing whole water and C18 extract is probably significant enough to explain the difference in attraction between paired samples. It is likely that the C18 extraction process isolated the effective compounds while filtering out negative or ineffective compounds, providing a stronger concentration of chemicals with positive aggregation effects.
In our study, since we delivered approximately natural concentrations of extract solutions at a rate of 11 $\mathrm{min}^{-1}$ into a background flow of $61 \mathrm{~min}^{-1}$, there was further dilution of the extract solution delivered to the fish. Yet, Abudefduf saxatilis still responded to this concentration of aggregation water extract, which suggests these C18-trapped compounds are highly attractive. Previous studies pinpointed DMSP as attractive to planktivorous fish (DeBose et al. 2008); however, A. saxatilis were attracted to compounds retained by C18, which does not bind DMSP. This finding begs the question of what suite of compounds are important in directing fish navigations to foraging hot-spots, and it provides specific targets for further inquiry into the chemistry underlying the attractiveness of fish aggregations. Perhaps fish are using these compounds in combination with others, such as DMSP, gaining information on the foraging behavior or presence of other fish, to navigate to foraging opportunities and productive locations.

Limited studies exist on chemical attractions of foraging aggregations and the mechanisms underlying such aggregation formation in the marine environment. However, Procellariiform seabirds utilize dimethyl sulfide (DMS), the breakdown product of DMSP that is produced by marine phytoplankton, to locate productive foraging grounds out at sea (Nevitt et al. 1995). These seabird aggregations can be composed of multiple species honing in on the visual and chemical cues of the growing aggregation, layered on top of the chemical cues (e.g. DMS) released from the underwater foraging cascade of phytoplankton, zooplankton, and fish (see DeBose \& Nevitt 2008). This chemical seascape is important not only for foraging seabirds but also for microbes (Seymour et al. 2010), plankton (reviewed by Steinke et al. 2002, see also Pohnert et al. 2007), and fish (DeBose et al. 2008, 2010). A multitude of studies have confirmed the idea that chemical seascapes surround coral reefs, driving larval recruitment (e.g. corals, other invertebrates, and fish) and adult behaviors (e.g. reproduction, foraging, etc.) (reviewed by Hay 2009); however, the particular mechanisms and chemical composition of these seascapes are still largely unknown (but see review by Paul et al. 2011).

Chemical signatures associated with fish aggregations potentially vary seasonally, with composition of the aggregations as well as with the plankton community, level of background chemicals and nutrients, and oceanographic conditions. These chemical cues might inform fish downstream that a 'hotspot' of foraging activity is occurring upstream and stimulate them to search for these opportunities. Further work 
identifying the compounds involved is needed to understand the mechanisms underlying fish aggregations, recruitment, and movement patterns over reef systems. Understanding these chemically mediated interactions is essential to predicting the behavior of fish as they follow transient chemical trails.

Acknowledgements. We gratefully acknowledge funding by the Smithsonian Marine Science Network, Caribbean Coral Reef Ecosystems (CCRE) Program and American Philosophical Society (to J.L.D.). We thank R. Baker, CCRE Station managers, field assistants, S. Gunasekera, W. Lee, T. Chalmers, S. Reed, H. Reichardt, and R. Ritson-Williams for support. Experiments adhered to IACUC guidelines. This work is contribution \#930 of the Smithsonian Marine Station and \#950 of the CCRE Program.

\section{LITERATURE CITED}

$>$ Davis MW, Spencer ML, Ottmar ML (2006) Behavioral responses to food odor in juvenile marine fish: acuity varies with species and fish length. J Exp Mar Biol Ecol 328:1-9

> DeBose JL, Nevitt GA (2007) Investigating the association between pelagic fish and DMSP in a natural coral reef system. Mar Freshw Res 58:720-724

> DeBose JL, Nevitt GA (2008) The use of odors at different spatial scales: comparing birds with fish. J Chem Ecol 34: 867-881

> DeBose JL, Lema SC, Nevitt GA (2008) Dimethylsulfoniopropionate (DMSP) as a foraging cue for reef fishes. Science 319:1356

> DeBose JL, Nevitt GA, Dittman AH (2010) Rapid Communication: experimental evidence that juvenile pelagic jacks (Carangidae) respond behaviourally to DMSP. J Chem Ecol 36:326-328

> Dittman AH, Quinn TP (1996) Homing in Pacific salmon: mechanisms and ecological basis. J Exp Biol 199:83-91

> Dixson DL, Jones GP, Munday PL, Pratchett MS, Srinivasan M, Planes S, Thorrold SR (2011) Terrestrial chemical cues help coral reef fish larvae locate settlement habitat surrounding islands Ecol Evol 1:586-595

> Elliott JK, Elliott JM, Mariscal RN (1995) Host selection, location, and association behaviors of anemonefishes in field settlement experiments. Mar Biol 122:377-389

Fine JM, Sorensen PW (2005) Biologically relevant concentrations of petromyzonol sulfate, a component of the sea lamprey migratory pheromone, measured in stream water. J Chem Ecol 31:2205-2210

> Gerlach G, Atema J, Kingsford MJ, Black KP, Miller-Sims V (2007) Smelling home can prevent dispersal of reef fish larvae. Proc Natl Acad Sci USA 104:858-863

> Gleason DF, Danilowicz BS, Nolan CJ (2009) Reef waters stimulate substratum exploration in planulae from brooding Caribbean corals. Coral Reefs 28:549-554

> Hara TJ (2006) Feeding behaviour in some teleosts is triggered by single amino acids primarily through olfaction. J Fish Biol 68:810-825

Hay ME (2009) Marine chemical ecology: chemical signals and cues structure marine populations, communities, and ecosystems. Annu Rev Mar Sci 1:193-212
Lecchini D, Planes S, Galzin R (2005a) Experimental assessment of sensory modalities of coral-reef fish larvae in the recognition of their settlement habitat. Behav Ecol Sociobiol 58:18-26

> Lecchini D, Shima J, Banaigs B, Galzin R (2005b) Larval sensory abilities and mechanisms of habitat selection of a coral reef fish during settlement. Oecologia 143:326-334

- Lecchini D, Waqalevu VP, Parmentier E, Radford CA, Banaigs B (2013) Fish larvae prefer coral over algal water cues: implications of coral reef degradation. Mar Ecol Prog Ser 475:303-307

Lürling M (2012) Infodisruption: pollutants interfering with the natural chemical information conveyance in aquatic systems. In: Bronmark C, Hansson LA (eds) Chemical ecology in aquatic systems. Oxford University Press, Oxford, p 250-271

Lürling M, Scheffer M (2007) Info-disruption: pollution and the transfer of chemical information between organisms. Trends Ecol Evol 22:374-379

> Mesquita RMRS, Canario AVM, Melo E (2003) Partition of fish pheromones between water and aggregates of humic acids. Consequences for sexual signaling. Environ Sci Technol 37:742-746

- Mitamura H, Arai N, Sakamoto W, Mitsunaga V and others (2005) Role of olfaction and vision in homing behaviour of black rockfish Sebastes inermis. J Exp Mar Biol Ecol 322:123-134

Munday PL, Dixsona DL, Donelson JM, Jones GP, Pratchett MS, Devitsina GV, Døving KB (2009) Ocean acidification impairs olfactory discrimination and homing ability of a marine fish. Proc Natl Acad Sci USA 106:1848-1852

> Nevitt GA, Veit RR, Kareiva P (1995) Dimethyl sulphide as a foraging cue for Antarctic Procellariiform seabirds. Nature 376:680-682

Nilsson GE, Dixson DL, Domenici P, McCormick MI, Sorensen C, Watson S, Munday PL (2012) Near-future carbon dioxide levels alter fish behavior by interfering with neurotransmitter function. Nature Clim Chang 2:201-204

Nordeng H, Bratland P (2006) Homing experiments with parr, smolt and residents of anadromous Arctic char Salvelinus alpinus and brown trout Salmo trutta: transplantation between neighboring river systems. Ecol Freshwat Fish 15:488-499

Paul VJ, Ritson-Williams R, Sharp K (2011) Marine chemical ecology in benthic habitats. Nat Prod Rep 28:345-387

Pohnert G, Steinke M, Tollrian R (2007) Chemical cues, defence metabolites and the shaping of pelagic interspecific interactions. Trends Ecol Evol 22:198-204

Seymour JR, Simo R, Ahmed T, Stocker R (2010) Chemoattraction to dimethyl-sulfoniopropionate throughout the marine microbial food web. Science 329:342-345

Steinke M, Malin G, Liss PS (2002) Trophic interactions in the sea: an ecological role for climate relevant volatiles? J Phycol 38:630-638

> Sweatman HPA (1988) Field evidence that settling coral reef fish larvae detect resident fishes using dissolved chemical cues. J Exp Mar Biol Ecol 124:163-174

> Vrieze LA, Sorensen PW (2001) Laboratory assessment of the role of a larval pheromone and natural stream odor in spawning stream localization by migratory sea lamprey (Petromyzon marinus). Can J Fish Aquat Sci 58:2374-2385

Wenger AS, Johansen JL, Jones GP (2011) Suspended sediment impairs habitat choice and chemosensory discrimination in two coral reef fishes. Coral Reefs 30:879-887 